\title{
E-HRM in Bangladesh
}

\author{
${ }^{1}$ Munshi Samaduzzaman, ${ }^{2}$ Fazluz Zaman \\ ${ }^{1}$ Adjunct lecturer, Central Queensland University, Australia \\ ${ }^{2}$ Adjunct lecturer, University of New South Wales, Australia
}

\begin{abstract}
Electronic Human Resource Management or what is known as e-HRM emphasizes an ordinary adopted executive practices in the field of manpower handling as well as sourcing. E-HRM is visibly grounded as well as established on diversely rooted expectations and constructive circumstances of e-HRM process, such as reduction of training and development costs, speeding up HR planning, improving manpower quality, and having a stronger strategic function for HR assumptions within the company. The utilization of e-HRM as well as its underlying technology, as a pathway to execute strategies, guidelines, practices as well as regulations pertaining to human resource, is ought to integrate an impact on how human resource role operates in the long run. Moreover, the use of e-HRM adhered to transform the system supported by HR base. The advantage of such e-HRM and its technology on Bangladesh as well as other countries in Asia such as Kuwait and Malaysia has put relevance on the e-HRM system with dependence on how e-HRM is manifested and applied into HRM division. For disadvantage, it can be that Asian countries may be too dependent on e-HRM applications and too much use of its technology without appropriate source of supports to the e-HRM function and the lack of construction base positing effective e-HRM related technology. This has affected Bangladesh and its industries in a serious manner as such; the business might be doing their best to accomplish with e-HRM goals through proper execution as well as adaptation within the business arena.
\end{abstract}

\section{Introduction}

Generally, Bangladesh is agro-based nation of which fifty percent of the population is working in farmlands (Ministry of Finance, GOB 2007). Nevertheless, the involvement of cultivation to Bangladesh GDP has exposed deteriorating trend in up to date duration (Bangladesh Bureau of Statistics, GOB 2007) and the need for the progress of industrial division has been understandable (Aowrangazab 2005). Conversely, it is moreover initiated that the presentation of private division business enterprises has not furthermore achieved ultimate accomplishment (Aowrangazab 2005; Khan 2007). An amount of issues are accountable for such condition of relationships in the community and the classified sector business enterprise of Bangladesh where unsuccessful HRM preparations are accounted to be single of them (Khan 2007). Despite its struggle, Bangladesh has marvellous potentialities in various parts. The significance of budding countries just like Bangladesh is increasing speedily as suppliers of inexpensive assets, buyer, competitor, resource users, and purpose of foreign straight deal of MNCs (Budhwar \& Debrah 2001). Bangladesh has major labour force of the globe (Ernst \& Young, \& MCCCI 2007). Bangladesh requires adopting sound human resource supervision practices (Beardwell and Holden as cited in Weeratunga 2003). The need to affirm of implementation of newfangled HRM performances through e-HRM process from within public along with private groups in Bangladesh and how e-HRM brings benefit for the latter.

\section{What is e-HRM?}

By means of e-HRM which is a manner of executing HR strategy, policy and practice. The e-HRM wires the HR meaning to conform in the company of HR requirements of the establishment throughout webtechnology channels (Ruel et al. 2004). Thus, e-HRM knowledge offers thresholds which enable managers, workers as well as HR experts to outlook, pull out, or modify sequence which is essential for overseeing the HR of an organisation. In addition, Lawler III (2005) recommended that e-HRM has characteristics that place a means of providing detailed HR performances. "With e-HRM, executives can contact applicable sequence and figures, make decision, and correspond with others. For case in point, an executive who desires to compose an advantage pay judgment might access records enclosing text, audio, as well as video recounting how paramount to create the assessment. Next, the executive can access the information folder holding information on workers. With a tick of mouse, the choice is confirm and other branches are informed (Lengnick-Hall \& Moritz 2003). Likewise, e-HRM uses web-based technology to make available HRM forces within employing organization. It holds e-recruitment along with e-learning, the primary fields of human resource administration to formulate extensive exercise of web-based know-how. From this foundation e-HRM has lengthened to hold close the liberation of practically every HR guiding principles. E-HRM is in real meaning the decentralization of HR roles to administration and workforce. They access these roles characteristically with intranet or further web- 
technology guides. The empowerment of executives and workers to act upon positive chosen HR function relieve the HR division of these errands, allow HR workforce to center fewer on the operational in addition to more fundamentals of $\mathrm{HR}$, as well as permitting organizations to subordinate HR division recruitment heights. It is expected that E-HRM is more unshakable in business background, the transformations will be noticeable, but to be obvious to a momentous quantity. Indeed, e-HRM is observed as contributing the budding to advance forces to HR division customers, get better competence and cost success surrounded by HR section, in addition to allowing the HR become a planned colleague in achieving executive goals through e-HRM pathways (Lengnick-Hall \& Moritz 2003).

\section{Advantage: How other countries in Asia are getting benefits?}

The benefit of e-HRM, merely on information, involves one direction communication to workers or managers all the way through web-based paths. The second benefit of e-HRM involves the computerization of business workflow, as well as supply chain combination wherein paperwork is substituted by electronic contribution. Administrators and workers can contact database, modernize sequence, look for essential information, and formulate decisions and from change of HR structure (Legnick-Hall \& Moritz 2003).

According to Ruël et al. (2004), the call for integration of HR purpose be capable of be an e-HRM objective. Even though, the authors established this objective within global organisations it is likely that e-HRM objective too can be initiated inside the public division as the implementation of Shared Service Centre HRM like that of Dutch Ministries (The committee Van Rijn 2001). There are circumstances for combination of HR role (Ruël et al. 2004) as expected that the acceptance of e-HRM involves the construction of HR purpose. In other expression, it is accepted that the implementation of e-HRM affect the errands of stakeholders of HR role for performing HR actions. When organisation has executed e-HRM, a number of HR activities are provided throughout net based-technologies as well as turn out to be the duty of executives or employees within the process.

Creating ground-breaking solution to advance process within companies is what every association would akin to to accomplish. Time is wealth, consequently, whichever equipment that would pace up company's actions, improve efficiency or cut costs, are being executed. Further advantage of e-HRM is cost reduction (Foster, 2010). Additionally, e-HRM makes use of tools such as Internet and software which in theory should facilitate the flow of information and communication between employees. It can also provide an online selection of employee trainings and courses, present valuable data easily accessible to all staff members (Paauwe et al. 2005). Most large organizations use e-HRM systems to attract future employees (Stone \& Lukaszewski 2009). Additionally, these systems are increasingly used to train employees, manage their performance and administer compensation and benefits (Gueutal \& Stone 2009). All aspects mentioned before sound appealing to any organization. However, prior e-HRM studies have not fully proven if these advances in HRM have had only positive effects. In some cases, it is believed that electronic systems cause negative attitudes of employees, since they lack personal communication and human interaction (Stone \& Lukaszewski, 2009).

\section{Disadvantages: In other countries in ASIA?}

The study of Lepak et al. (2003) states that there are three levels of analysing the HR system and that consideration of all the three levels are important to understand HRM in practice. E-HRM wires and automates HRM process through the utilization of IT. In Asia there is increase in Information Technologies, but the alteration to e-HRM is going quite slow. Thus, HRM is developed and the top management does have the skills. HR administrators have little status and they are not properly trained. HRM and e-HRM simply will add strength if the countries in Asia and will be pleased about the strategic significance of HRM role (Mellahi \& Budhwar 2006). So if an Asian country like Malaysia wants to execute e-HRM on a huge extent, something has to transform in the estimation as well as the situation of HRM in the business along with the HR director in the business. If Malaysia wants to battle with the rest of the globe, the alteration to e-HRM has to be faster and HRM has to be more urbanized. It is expected that the HR professionals require additional skills to cope with the change of focus and technology maintenance responsibilities. The increased responsibilities require skills of the HR professionals as they should receive proper training and education to be able to carry the responsibilities of such a role (Ruël et al. 2004, Stanton \& Coovert 2004). Additionally, if workforce is not correctly trained in the practice of e-HRM it may outcome in slower job presentation and enlarged extensive costs.

More disadvantages are hooked on the lack of staff, the lack of a budget, problems with time management, the need to work with other departments and the lack of information technology support (Parry, and Wilson, 2009). Pressures of e-HRM Lepak and Snell (1998) identified four pressures of e-HRM. HRM departments are asked to focus on strategic questions and that departments need to be flexible (Payne et al. 2009). 


\section{Focus on Bangladesh: How these advantages can bring success for \\ Bangladesh? How the disadvantages can be overcome?}

The presumption nevertheless, depicts what the responsibility of e- HRM knowledge in the establishment such as in Asia and in Bangladesh as well. Lepak \& Snell (1998) recommended that IT can persuade the incorporation of HR purpose, at what time the errands for performing HR performances are distributed. IT can pressure functional integration of HR role. This presumption is exercised by Ruel et al. (2004) for the labelling of e-HRM knowledge in:

- $\quad$ Functioning e-HRM

- Relational e-HRM

- Transformational e-HRM

Functioning e-HRM knowledge is apprehensive with the fundamental HR performance in the executive district. For instance, workers keeping their personal information brand new throughout an HR gateway. Relational e-HRM concerns more on sophisticated HR performance. The accent at this juncture is on equipment that holds up necessary HR process such as for employment as well as selection of fresh staff. Transformational e-HRM know-how is apprehensive through HR actions with a tactical nature as for case in point, creating an alteration equipped labour force throughout e-HRM machinery that facilitates the employees to increase in stripe with company's planned choice (Ruël et al. 2004).

The theory of Snell et al. (1996) in addition to Lengnick-Hall \& Moritz (2003) can be utilized as preliminary points for the growth of an innovative typology to find out the variety of e-HRM support the knowledge presents. This can be applied to obtain insights in dissimilarities in how IT can be employed to hold up e-HRM benefits that are reflected in Asian countries like Kuwait and Malaysia (refer to the diagrams below for clearer picture of e-HRM benefits and advantages)

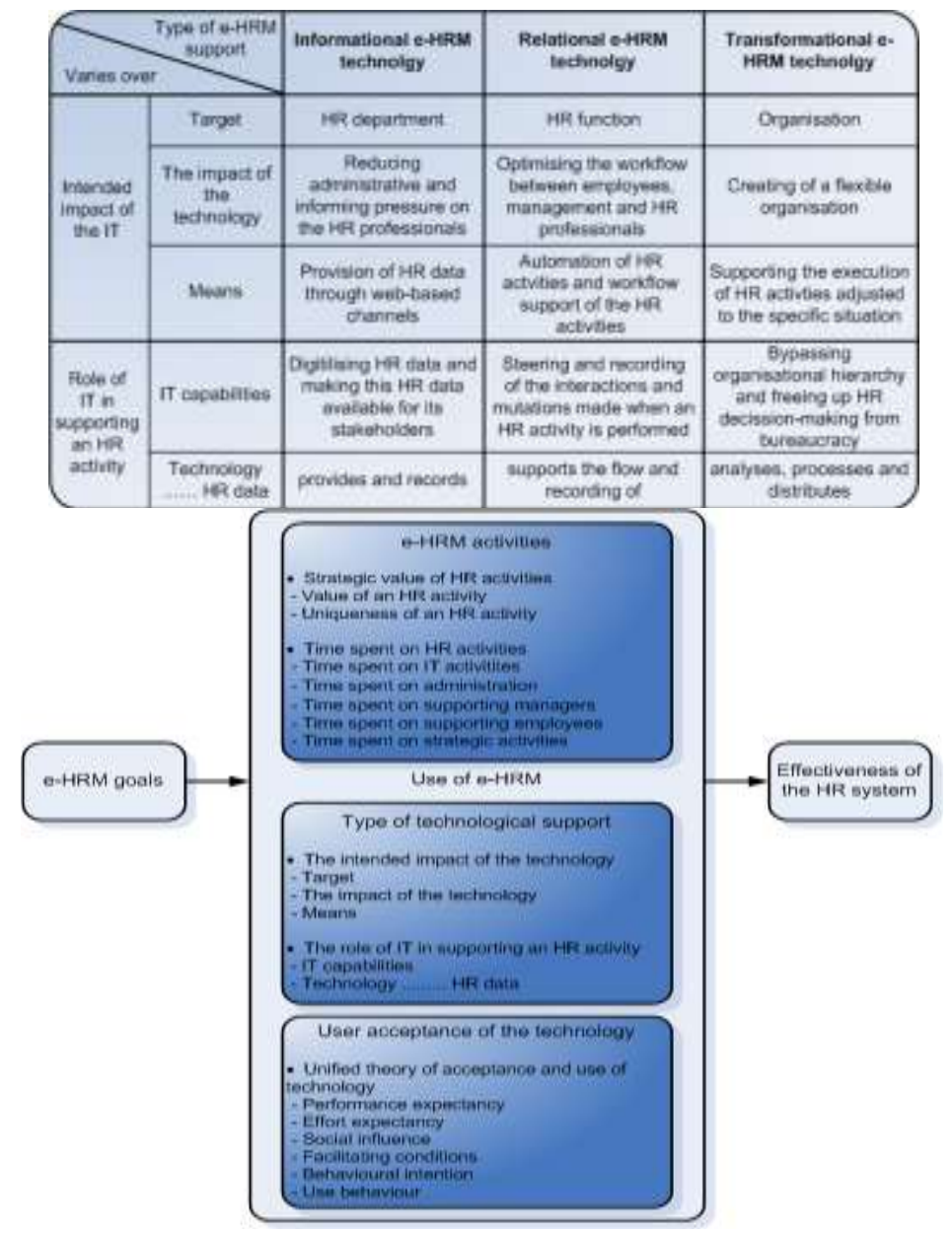

However, it is ideal that certain e-HRM purposes as well as its actual utilization within e-HRM technology poses valuable effect on HR systems from within business grounds. Bangladesh industries that use e-HRM gradually rely on visible, acceptable as well as transparent measures to generate good business case such as those relevant for making ample investment ways (Lengnick-Hall \& Moritz 2003, p. 369). Several statistics employed to justify the business generated in e-HRM technologies are for instance the minimum 
charge of e-HRM transaction as cycle occasions as well as the headcount transformations in human resource department in addition to finance metrics like the ROI and timeframe of salary period and the procedures of workforce satisfaction as brought about by e-HRM effectiveness (Lengnick-Hall \& Moritz 2003). In addition, through e-HRM conduction, the constructive side that can be ideal for Bangladesh and other Asian countries recognize metrics value upon identification of formal commerce situations such as those that link with productivity enhancements within Bangladesh based industry, such ROI and augmented workforce interactions from within e-HRM adaptability (Stone, Stone-Romero \& Lukaszewski 2006).

Preferably, it is significant to be familiar with how the presentation or efficiency of HR structure can be calculated. The efficacy of HR scheme is seriously discussed (Stone, Stone-Romero, and Lukaszewski, 2006). Some focus exclusively on financial statistics similar to return on venture, possessions or equity whereas others spotlight on balanced score tag to congregate previous information as well as client and worker suggestions (Lengnick-Hall \& Moritz 2003). It is likely that the exercise of e-HRM knowledge has an impact on presentation as it is expected that the execution of e-HRM speed up business processing, reduce sequence error, and improve the pathway and management of HR performance. Ruël et al. (2004) declared that implementation of e-HRM technology require HR knowledge for the regeneration of instruments as well as arrange these instruments for simple web-based utilization. There is anticipation that the taking up of e-HRM technology lead to HR experts being practical authority supporting workers and executives as a substitute of being executive specialists.

\section{Limitations}

The e-HRM knowledge should not merely be considered to compose the HR processes as competent and contemptible as likely, but the e-HRM machinery should be ready and useable as well, to augment the service know-how of the executives and workforce. In this approach a customer service upgrading of HR structure can be attained (Ruël et al. 2004). However, based on dissimilar experiential plus theoretical studies demeanor in the western globe, most practices such as HR preparation, staffing, selection, encouragement, presentation assessment, payment and business relationships were not perform accurately in the industry. There are areas where limitations of e-HRM are bounded like, a study might be assumed to assess the change with admiration to position of e-HRM practices in industrial enterprises of Bangladesh and other countries in Asia.

\section{Conclusion}

It has been uncovered that the status of e-HRM in Bangladesh is reasonably acceptable whereas the general status of the latter is found to be satisfactory. It is unearthed that significant difference is prevailing between industrial enterprises of Bangladesh that are in significantly better position. Obviously, e-HRM is new and intriguing field of study at the junction of human resource administration as well as information system. Consequently, to connect potentialities, the enterprises need to accept sound human resource executive practice. Also, thorough study to evaluate e-HRM is applicable and valuable how the benefits bring appropriate applications in the long-run.

Therefore, through e-HRM workers manage their individual private information. They are able to modernize records when their positions transform and make numerous assessments on their hold, seeing HR experts if necessary. Also, e-HRM benefits are colossal of which not just large businesses even SME's can furthermore take on the e-HRM and the consequence positively will be further encouraging. By means of eHRM scheme workers can help other HR employees to be concerned with premeditated issues for the business. The execution of e-HRM seeks to remove intrusion from human resources and provide access to the managers as well as individuals to carry out tasks unswervingly with the e-HRM tools. As majority of the industry in Bangladesh have web access in current occasion, the longing from the administration is to establish their eHRM nowadays. Unluckily, several industries in Bangladesh necessitate going extensive concerning assumption of e-HRM and obtain the finest benefits from the e-HRM. However, e-HRM adoption in Bangladesh will be in complete form soon in the upcoming years.

\section{References}

[1] GOB, Bangladesh Bureau of Statistics 2007, Statistical pocket book of Bangladesh 2006, Dhaka

[2] GOB, Ministry of Finance 2007, Bangladesh economic review 2007, Dhaka

[3] Aowrangazab, A 2005, 'Industrialization process in Bangladesh: An evaluation of the role of state, policy measures, strategies, problems, and prospects', Unpublished doctoral dissertation, University of Chittagong, Bangladesh

[4] Budhwar, P \& Debrah, YA (eds) 2001, Human resource management in developing countries, London: Routledge.

[5] Ernst \& Young, \& Metropolitan Chamber of Commerce and Industry (MCCI) 2007, HR practices survey- Bangladesh. Dhaka

[6] Weeratunga, L 2003, Human resource management. Dhaka: Bangladesh Open University.

[7] Khan, MM 2007, 'Enhancing institutional capacity of public administration' in Bangladesh: Present state and future direction', in Development issues of Bangladesh-III, eds Islam, M \& Andaleeb, S, pp. 111-134, Dhaka: UPL.

[8] Ruel, H, Bondarouk, T \& Looise, JK 2004, Management Review, vol. 15, no. 2, pp. 364-380.

[9] Lengnick-Hall, ML \& Moritz, S 2003,' The impact of e-HR on the human resource management function', Journal of Labor Research, vol. 24, no. 3, pp. 365-379. 
[10] Paauwe, J, Farndale, E \& Williams, R 2005, 'Web-Based Organizing in Traditional Brickand-Mortar Companies: The Impact on HR', in e-Human Resources Management: Managing Knowledge People, eds T. Torres-Coronas \& M. Arias-Oliva, , pp. 31-67.

[11] Stone, DL, Stone-Romero, EF \& Lukaszewski, KM 2006, 'Factors affecting the acceptance and effectiveness of electronic human resource systems', Human Resources Management Review, vol. 16, no. 2, pp. 229-244.

[12] Stanton, JM \& Coovert, MD 2004, 'Turbulent waters: The intersection of information technology and human resources', Human Resource Management, vol. 43, no. 22, pp. 121-125

[13] Gueutal, HG \& Stone, DL 2009, The brave new world of eHR: human resources management in the digital age (1st ed.), California: Jossey-Bass.

[14] Stone, DL \& Lukaszewski, KM 2009, 'An expanded model of the factors affecting the acceptance and effectiveness of electronic human resource management systems', Human Resources Management Review, vol. 19, pp. 134-143

[15] Lepak, DP \& Snell, SA 1998, 'Virtual HR: Strategic human resource management in the 21st century', Human Resource Management Review, vol. 8, no. 3, pp. 215-234.

[16] Parry, E \& Wilson, H 2009, 'Factors influencing the adoption of online recruitment', Personnel Review, vol. 38, no. 6, pp. 655673.

[17] Payne, SC, Horner, MT, Boswell, WR, Schroeder, AN, Stine-Cheyne, KJ 2009, 'Comparison of online and traditional performance appraisal systems', Journal of Managerial Psychology, vol. 24, no. 6, pp. 526-544. 